\title{
Warming-induced permafrost thaw exacerbates tundra soil carbon decomposition mediated by microbial community
}

\author{
Jiajie Feng ${ }^{1 \dagger}$, Cong Wang ${ }^{1 \dagger}$, Jiesi Lei ${ }^{2}$, Yunfeng Yang ${ }^{2^{*}}$ (D), Qingyun Yan ${ }^{1,3,4}$, Xishu Zhou $^{1,2,5}$, Xuanyu Tao ${ }^{1}$, \\ Daliang Ning ${ }^{1}$, Mengting M. Yuan ${ }^{1}$, Yujia Qin ${ }^{1}$, Zhou J. Shi ${ }^{1}$, Xue Guo ${ }^{1,2}$, Zhili He $^{1,3,4}$, Joy D. Van Nostrand ${ }^{1}$, \\ Liyou Wu' ${ }^{1}$, Rosvel G. Bracho-Garillo ${ }^{6}$, C. Ryan Penton ${ }^{7,8}$, James R. Cole ${ }^{9}$, Konstantinos T. Konstantinidis ${ }^{10}$, Yiqi Luo ${ }^{11}$, \\ Edward A. G. Schuur ${ }^{11}$, James M. Tiedje ${ }^{9,12}$ and Jizhong Zhou ${ }^{1,2,13^{*}}$
}

\begin{abstract}
Background: It is well-known that global warming has effects on high-latitude tundra underlain with permafrost. This leads to a severe concern that decomposition of soil organic carbon (SOC) previously stored in this region, which accounts for about $50 \%$ of the world's SOC storage, will cause positive feedback that accelerates climate warming. We have previously shown that short-term warming (1.5 years) stimulates rapid, microbe-mediated decomposition of tundra soil carbon without affecting the composition of the soil microbial community (based on the depth of 42684 sequence reads of $16 \mathrm{~S}$ rRNA gene amplicons per $3 \mathrm{~g}$ of soil sample).

Results: We show that longer-term (5 years) experimental winter warming at the same site altered microbial communities $(p<0.040)$. Thaw depth correlated the strongest with community assembly and interaction networks, implying that warming-accelerated tundra thaw fundamentally restructured the microbial communities. Both carbon decomposition and methanogenesis genes increased in relative abundance under warming, and their functional structures strongly correlated $\left(R^{2}>0.725, p<0.001\right)$ with ecosystem respiration or $\mathrm{CH}_{4}$ flux.

Conclusions: Our results demonstrate that microbial responses associated with carbon cycling could lead to positive feedbacks that accelerate SOC decomposition in tundra regions, which is alarming because SOC loss is unlikely to subside owing to changes in microbial community composition.
\end{abstract}

\section{Background}

High-latitude permafrost-underlain tundra ecosystems have been a hotspot for climate change research, owing to their substantial carbon (C) pool and high vulnerability to climate warming [1-4]. Old C from plant and animal remnants has been sequestered in permafrost regions for thousands of years under frozen soil conditions [5]. Although accounting for only $15 \%$ of the total

\footnotetext{
* Correspondence: yangyf@tsinghua.edu.cn; jzhou@ou.edu

†jiajie Feng and Cong Wang contributed equally to this work.

${ }^{2}$ State Key Joint Laboratory of Environment Simulation and Pollution Control,

School of Environment, Tsinghua University, Beijing 100084, China

'Institute for Environmental Genomics, Department of Microbiology and

Plant Biology, University of Oklahoma, Norman, OK 73019, USA

Full list of author information is available at the end of the article
}

global land mass, the northern hemisphere permafrost regions at a depth of $0-3 \mathrm{~m}$ contain $1672 \mathrm{Pg} \mathrm{C}$, roughly half of the global soil $C$ pool $[2,6]$. Since permafrost regions have the potential to release a large amount of previously stored soil $\mathrm{C}$ to the atmosphere in a warmer world $[3,4]$, it is a significant variable that affects the future trajectory of climate change [7].

Over the past 30 years, annual average temperatures in high latitude regions have increased by $0.6{ }^{\circ} \mathrm{C}$ per decade, twice as fast as the global average [8], resulting in the substantial thaw of permafrost soils. It has been estimated that climate warming will cause a reduction of $30-70 \%$ of the total permafrost soils by the end of the twenty-first century [9]. As a consequence, previously

(C) The Author(s). 2020 Open Access This article is distributed under the terms of the Creative Commons Attribution 4.0 International License (http://creativecommons.org/licenses/by/4.0/), which permits unrestricted use, distribution, and 
protected soil $\mathrm{C}$ becomes available for microbial decomposition [2]. A number of studies have shown that tundra soil $C$ is highly vulnerable and responds rapidly to the warming-induced thaw of permafrost soils $[2,4,10]$. Although the increase in soil $\mathrm{C}$ input by higher plant productivity across the tundra regions could partially offset soil C loss [11-13], there remains a lack of a mechanistic understanding of microbial responses to climate warming, which makes it challenging to assess the future $\mathrm{C}$ balance.

Only a few studies of permafrost ecosystems have examined microbial responses to climate warming $[4,7,14]$. For example, a substantial fraction of permafrost soil $\mathrm{C}$ was available for microbe-mediated decomposition during a lab incubation simulating warming [15]. Consistently, a field study in a permafrost-based tundra (the same site as this study) revealed that microbial community functional potential was highly sensitive to a 1.5-year experimental warming, despite the taxonomic composition remaining unaltered [4]. As a result, soil $\mathrm{C}$ was more vulnerable to microbial decomposition. However, it remains unclear whether microbial responses to short-term warming persist in the longer term.

Since a 1.5-year warming altered the microbial functional structure but not the taxonomic composition of soil microbial communities in permafrost-based tundra [4], our central hypothesis was that 5 years' warming could induce changes in plant productivity, soil microclimate, and soil microbial community structure. We expected three mutually exclusive outcomes after longerterm warming: (i) similar to that observed after the 1.5year warming period, the microbial functional structure would be altered, while the taxonomic composition would remain similar to that of the control group (resistance); (ii) the microbial communities that are acclimated to experimental warming would manifest a functional structure and taxonomic composition that approximates that of the control group (resilience); or (iii) microbial communities would continue to evolve into new states and both functional structure and taxonomic composition would be altered by warming (sensitivity).

To test our hypothesis, we examined soil microbial communities subjected to a 5 -year winter warming treatment at the Carbon in Permafrost Experimental Heating Research (CiPEHR) site located in Alaska, USA. This site has been extensively used to analyze the effects of climate warming on plants, soil nitrogen $(\mathrm{N})$ availability, and soil microbial communities [4, 16-18]. A winter warming treatment was carried out by snow fences ( $1.5 \mathrm{~m}$ tall and $8 \mathrm{~m}$ long), which warmed the soil by maintaining thick snow layers as heat insulators. We investigated both the taxonomic composition and functional structure of microbial communities under warming, in addition to potential drivers and ecological consequences of community changes. Specifically, the taxonomic composition of microbial communities was investigated by amplicon sequencing of $16 \mathrm{~S}$ rRNA genes for bacterial/archaeal community and internal transcribed spacer (ITS) region for the fungal community. The microbial functional structure was examined by a functional microarray named GeoChip 5.0M [19].

\section{Results \\ Edaphic factors, plant productivity, and ecosystem C fluxes}

As shown in Additional file 1: Table S1, the average winter soil temperature increased by $0.63{ }^{\circ} \mathrm{C}(p=0.037)$ under warming and the maximum thaw depth increased by $11.37 \mathrm{~cm}(p=0.006)$, much more substantial than the $4.78 \mathrm{~cm}$ increase after the 1.5-year warming [4]. Aboveground plant biomass at the end of the growth season increased by $25.2 \%$ ( $p=0.049)$ under warming, similar to other observations in tundra regions [11-13]. Ecosystem respiration increased by $72.8 \%(p<0.001)$ under warming, and $\mathrm{CH}_{4}$ flux increased by $218.8 \%(p=0.004)$.

\section{Microbial community composition}

We examined the taxonomic composition of microbial communities via high-throughput amplicon sequencing of bacterial and archaeal 16S rRNA genes and the fungal internal transcribed spacer (ITS) region. After resampling at 34.673 reads per sample, 5117 OTUs were generated by $16 \mathrm{~S}$ rRNA gene amplicon sequencing. Almost all of the OTUs $(99.86 \%)$ and relative abundance (99.88\%) belonged to bacteria, with 2740 OTUs mapping to 214 known genera. Proteobacteria was the most abundant phylum (31.00\% in relative abundance), followed by Acidobacteria (30.61\%), Actinobacteria (12.08\%), and Verrucomicrobia (8.34\%) (Additional file 1: Figure S1a). Among Proteobacteria, the relative abundance of Alphaproteobacteria was $13.86 \%$ and that of Gammaproteobacteria was 7.74\%. For fungi, 1465 OTUs were generated by ITS amplicon sequencing after resampling at 19242 reads per sample. Leotiomycetes were the most abundant class $(47.35 \%$ in relative abundance), followed by Eurotiomycetes (18.85\%), unidentified Ascomycota (16.06\%), and Agaricomycetes (10.05\%) (Additional file 1: Figure S1b).

Warming increased the phylogenetic $\alpha$-diversity of the bacterial communities (Faith's $P D, p=0.032$, Fig. 1a) but not the fungal communities, probably due to high fungal variance among a limited number of biological replicates $(p=0.406$, Fig. $1 b)$. Bacterial within-group $\beta$-diversity, i.e., the difference within biological replicates, was also increased in warmed samples $(p<0.001$, Fig. $1 c)$, indicating that warming led to more divergent bacterial communities. In contrast, fungal within-group $\beta$ diversity remained unchanged ( $p=0.143$, Fig. 1d). All of the nonparametric multivariate statistical tests of 

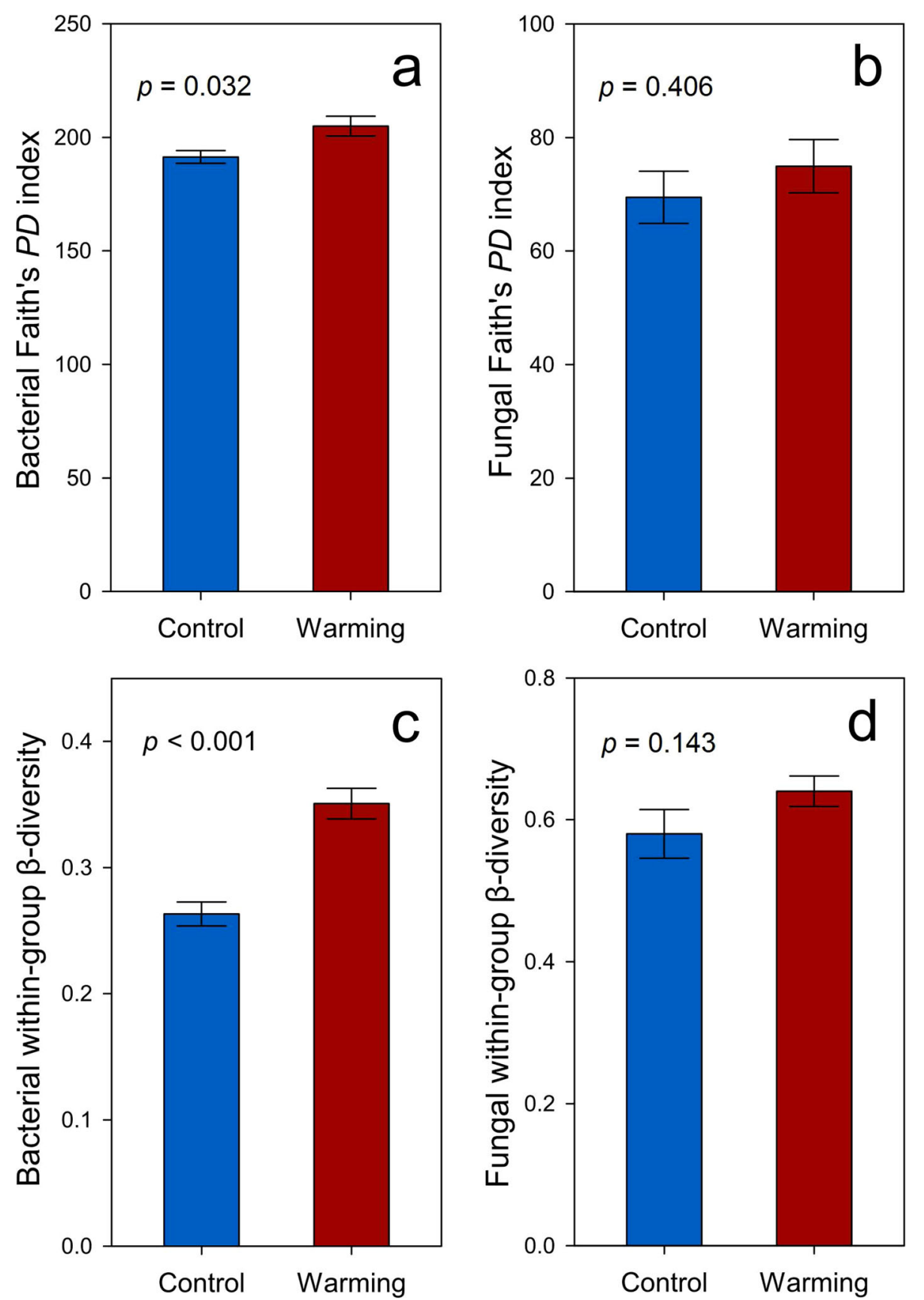

Fig. 1 Diversity indices of bacterial/fungal communities, including a bacterial Faith's PD index (phylogenetic a-diversity index), $\mathbf{b}$ fungal Faith's $P D$ index, $\mathbf{c}$ bacterial within-group $\beta$-diversity (Bray-Curtis distance), and $\mathbf{d}$ fungal within-group $\beta$-diversity (Bray-Curtis distance). Statistical significances were determined by permutation $t$ tests. Error bars represent standard error of the mean for $n=6$ biological replicates

dissimilarity (MRPP, ANOSIM, and Adonis) showed that warming altered the composition of the bacterial communities but not the fungal communities $(p<0.040$, Table 1).

\section{Microbial correlation networks}

All bacterial and fungal networks generated from control or warmed samples showed topological properties of small-world, scale-free, and modularity, and were significantly different from randomly generated networks (Additional file 1: Table S2). The average connectivity of the bacterial network in warmed samples was higher ( $p$ $<0.001)$, but the average geodesic distance was lower $(p$ $<0.001)$ than those in the control samples, suggesting that nodes were more connected in warmed samples. In contrast, the average connectivity and the average 
Table 1 Dissimilarity tests of warming effects on microbial taxonomic composition revealed by $16 \mathrm{~S}$ rRNA gene and ITS sequencing, and functional structure revealed by GeoChip

\begin{tabular}{|c|c|c|c|c|c|c|}
\hline \multirow[t]{2}{*}{ Dataset } & \multicolumn{2}{|l|}{ MRPPa } & \multicolumn{2}{|c|}{ ANOSIM } & \multicolumn{2}{|c|}{ Adonis } \\
\hline & delta & $p$ & $r$ & $p$ & r2 & $p$ \\
\hline 16S rRNA gene & 1338.991 & $0.040 \mathrm{~b}$ & 0.152 & 0.028 & 0.162 & 0.015 \\
\hline ITS & 0.610 & 0.741 & 0.067 & 0.722 & 0.070 & 0.738 \\
\hline GeoChip & 0.001 & 0.012 & 0.296 & 0.012 & 0.166 & 0.009 \\
\hline
\end{tabular}

${ }^{a}$ Three permutation tests were performed, including the multiple response permutation procedure (MRPP), analysis of similarity (ANOSIM), and permutational multivariate analysis of variance (Adonis). Bray-cutis distance was used in the permutation tests

${ }^{\mathrm{b}}$ Bold values indicate $p<0.050$

geodesic distance of fungal networks were reduced by warming $(p<0.001)$, owing to increased network modularity (Additional file 1: Table S2).

To explore the relationship between network topology and environmental factors, we included environmental factors as nodes in the networks. Thaw depth had the highest node connectivity in the bacterial network of warmed samples (Additional file 1: Figure S2a), while water table depth had the highest node connectivity in the bacterial network of control samples (Additional file 1: Figure S2b). In contrast, thaw depth, bulk density and soil $\mathrm{N}$ had the highest node connectivity in the fungal network of warmed samples (Additional file 1: Figure S2c), while bulk density and soil $\mathrm{N}$ showed the highest node connectivity in the fungal network of control samples (Additional file 1: Figure S2d).

\section{Microbial community functional structure}

A total of 38484 probes on the GeoChip showed positive signals. All of the nonparametric multivariate statistical tests of dissimilarity (MRPP, ANOSIM, and Adonis) showed that the overall functional structure of soil microbial communities was altered by warming $(p<0.012$, Table 1), and positively correlated with bacterial and fungal community composition $(p<0.015$, Additional file 1 : Figure S3). The relative abundance of genes associated to $\mathrm{C}, \mathrm{N}$, phosphorus $(\mathrm{P})$, and sulfur $(\mathrm{S})$ cycling was increased by warming (Fig. 2 and Additional file 1: Figure S4). In contrast, only nine functional genes, which mainly belong

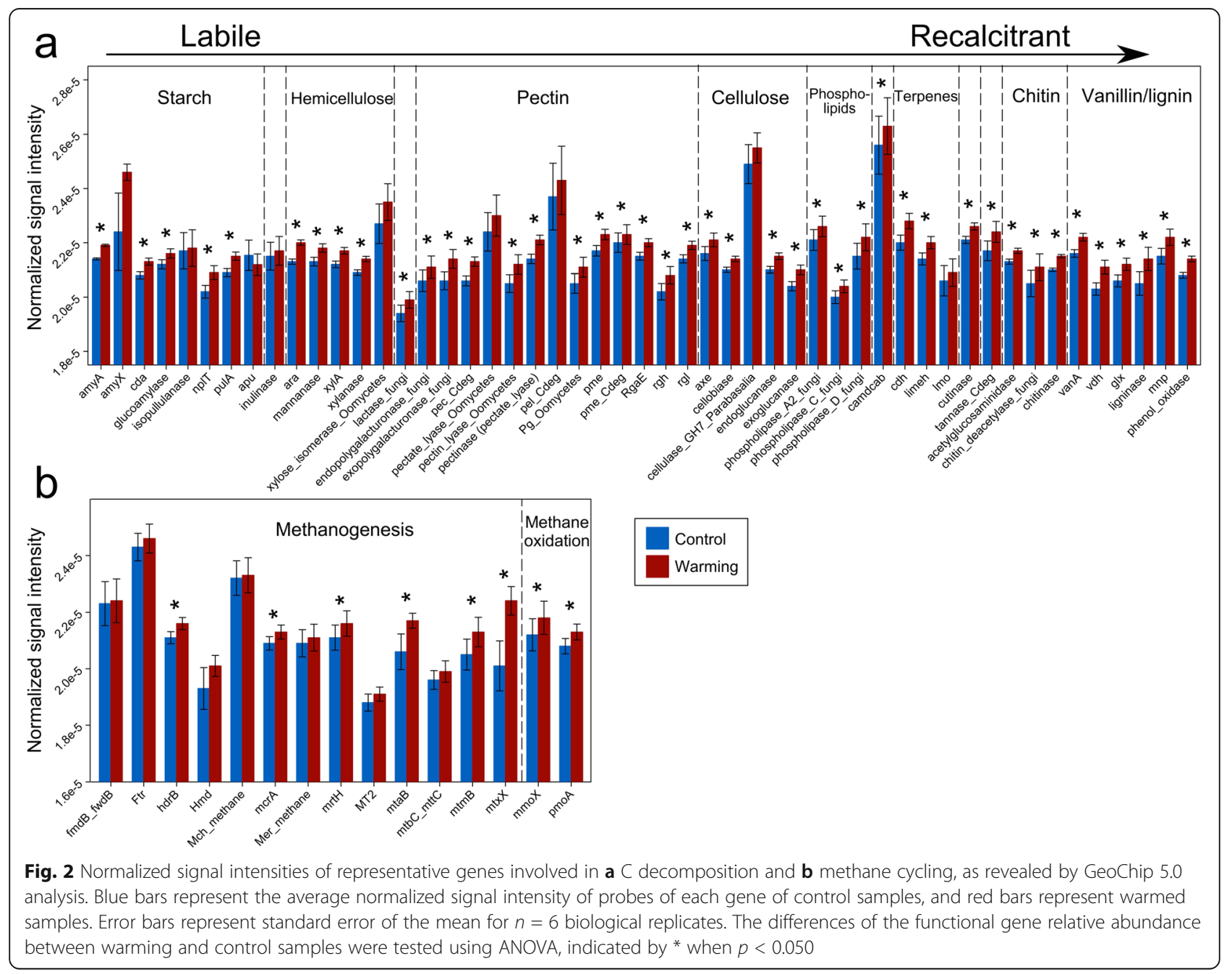


to functions related to virulence and virus, were significantly $(p<0.05)$ decreased in relative abundance.

\section{C cycling}

We detected 50 genes associated with decomposition of labile or recalcitrant C. Among them, 42 genes exhibited higher relative abundance in warmed samples than control samples $(p<0.038$, Fig. 2a), including amyA encoding amylase, $x y l A$ encoding xylose isomerase, exoglucanase, cellobiase, pectate lyase, phenol oxidase, $v d h$ encoding vanillin dehydrogenase, and ligninase.

A total of 13 methanogenesis genes were detected (Fig. 2b). Among them, mcrA encoding methyl coenzyme $\mathrm{M}$ reductase, $\mathrm{mrtH}$ encoding tetrahydromethanopterin S-methyltransferase, $m t a B$ encoding methanolcobalamin methyltransferase, $m t m B$ encoding monomethylamine methyltransferase, $m t x X$ encoding methyltransferase, and $h d r B$ encoding $\mathrm{CoB} / \mathrm{CoM}$ heterodisulfide reductase exhibited higher relative abundance in warmed samples $(p<0.007)$, suggesting a higher functional potential of methanogenesis. In addition, both methane oxidation genes, which are $m m o X$ encoding soluble methane monooxygenase and $p m o A$ encoding particulate methane monooxygenase, exhibited higher relative abundance in warmed samples $(p<0.001$, Fig. 2b).

Higher functional capacities of microbial $C$ degradation and methanogenesis in warmed samples could lead to in situ C loss. Accordingly, we detected strong correlations between functional structure of $\mathrm{C}$ decomposition genes and in situ ecosystem respiration $\left(R^{2}=0.725, p<\right.$ 0.001 , Fig. 3a), and between the functional structure of methanogenesis genes and in situ $\mathrm{CH}_{4}$ flux $\left(R^{2}=0.772\right.$, $p<0.001$, Fig. 3b).

\section{$N$ cycling}

As a limiting nutrient in tundra ecosystems, $\mathrm{N}$ plays an essential role in ecosystem productivity. All the detected genes associated with $\mathrm{N}$ cycling exhibited higher relative abundance in warmed samples $(p<0.025$, Additional file 1 : Figure S4a), suggesting that warming enhanced microbial functional capacity for $\mathrm{N}$ cycling. These genes included the $\mathrm{N}$ fixation gene (nifH encoding nitrogenase reductase), nitrification gene (hao encoding hydroxylamine oxidoreductase), denitrification genes (e.g., narG encoding nitrate reductase), dissimilatory nitrate reduction genes (e.g., nap $A$ encoding periplasmic nitrate reductase), assimilatory nitrate reduction genes (e.g., nas $A$ encoding assimilatory nitrate reductase), $\mathrm{N}$ mineralization gene (ureC encoding urease), and ammonia assimilation gene ( $g d h$ encoding glutamate dehydrogenase).

\section{$P$ and $S$ cycling}

$\mathrm{P}$ deficiency is common in global soil ecosystems. We found that $\mathrm{P}$ cycling genes including phytase and $p p x$ encoding exopolyphosphatase ( $p p x)$ were in higher relative abundance in the warmed samples $(p<0.001$, Additional file 1: Figure S4b), suggesting that warming could potentially increase microbial functional capacity of P cycling. Similarly, 27 genes associated with S cycling were detected, of which 21 showed higher relative abundance in warmed samples $(p<0.027$, Additional file 1 : Figure $\mathrm{S} 4 \mathrm{c}$ ). These genes included $d s r A / B$-encoding dissimilatory sulfite reductase, $\mathrm{SiR}$ - and $c y s I / J$-encoding sulfate reductase, and soxY-encoding sulfur oxidation protein.

\section{Microbial community assembly mechanisms and the importance of thaw depth}

To assess the importance of deterministic and stochastic processes in shaping soil community composition, stochastic ratios were calculated. Stochastic processes of bacterial communities were reduced by warming from 91.5 to $65.9 \%$ $(p<0.001$, Additional file 1: Figure S5a), suggesting that environmental filtering was elicited by warming. Similarly, stochastic ratios of fungal communities were reduced by warming ( $p=0.036$, Additional file 1: Figure S5b).

To identify environmental factors that may have a strong effect on the microbial communities, we performed correlation tests between the beta-nearest taxon index ( $\beta$ NTI, also known as phylogenetic $\beta$-diversity) [20] and pairwise differences in all of 14 environmental factors. Bacterial $\beta$ NTI correlated with the thaw depth $\left(R^{2}=\right.$ 0.503, $p<0.001$, Fig. 4a), and to a lesser extent with soil moisture $\left(R^{2}=0.128, p<0.001\right.$, Fig. $\left.4 \mathrm{~b}\right)$ and aboveground plant biomass $\left(R^{2}=0.158, p<0.001\right.$, Fig. 4c). Fungal $\beta$ NTI had weaker correlations with those factors than bacterial $\beta$ NTI, but correlated with thaw depth $\left(R^{2}=0.067, p=\right.$ 0.038, Fig. 4d) and soil moisture $\left(R^{2}=0.085, p=0.013\right.$, Fig. 4e) while not with aboveground plant biomass $\left(R^{2}=\right.$ $0.001, p=1.000$, Fig. 4f).

We performed CCA to verify the importance of the thaw depth in microbial community assembly. The bacterial community composition correlated with thaw depth, aboveground plant biomass, soil moisture, and winter soil temperature, with soil moisture and aboveground plant biomass being the most important variables $(p=0.007$, Additional file 1: Figure S6a). Similarly, thaw depth, aboveground plant biomass, soil moisture, winter soil temperature and soil $\mathrm{C} / \mathrm{N}$ ratio correlated with the fungal community composition $(p=0.012$, Additional file 1 : Figure S6b) and with the microbial functional structure $(p<0.001$, Additional file 1: Figure S6c).

\section{Discussion}

Given the tremendous amount of soil $\mathrm{C}$ stored within permafrost regions and its high vulnerability to climate warming, microorganisms have been recognized as the key to mediate the impact of climate warming on 

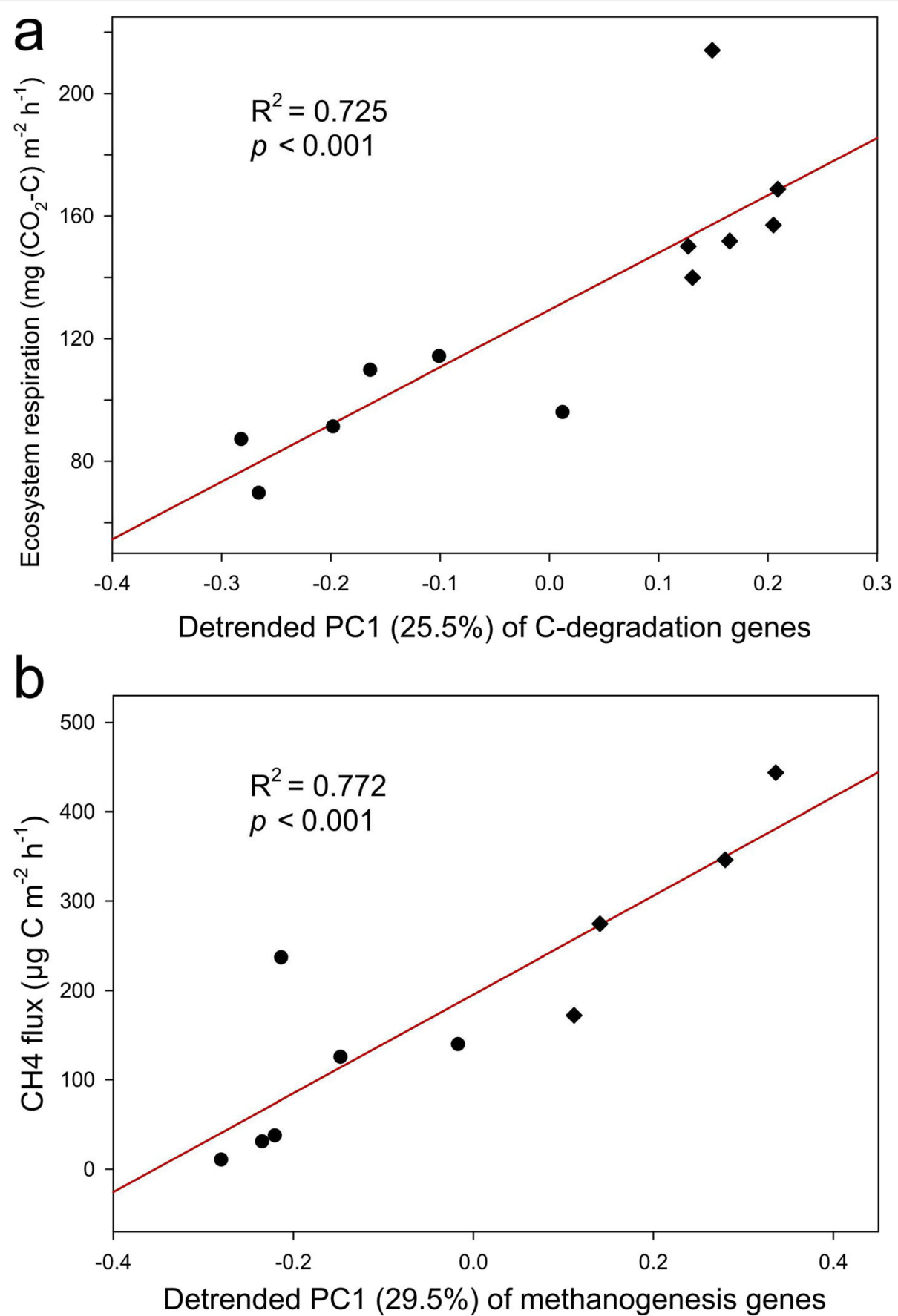

Fig. 3 Linear regressions between a in situ ecosystem respiration and the first detrended principle component (PC1) of C decomposition genes, and $\mathbf{b}$ in situ methane flux and PC1 of methanogenesis genes. Each point represents a biological replicate of warming (diamonds) or control (circles) samples

permafrost region soil C [21]. In contrast to the previous observation at our study site that bacterial community taxonomic composition was unaltered by 1.5 -year warming [4], we showed here that 5-year warming caused significant changes in the bacterial community composition, functional structure, and correlation networks (Table 1 and Additional file 1: Table S2). Our findings support the hypothesis that bacterial communities continue to evolve and diverge into new states (sensitivity) after long-term warming. Consequently, the higher functional capacity of microbial decomposition of soil $\mathrm{C}$ under warming contributes to higher soil respiration and $\mathrm{CH}_{4}$ flux, which in turn accelerates tundra $\mathrm{C}$ loss. Those observations are likely arising from changes 

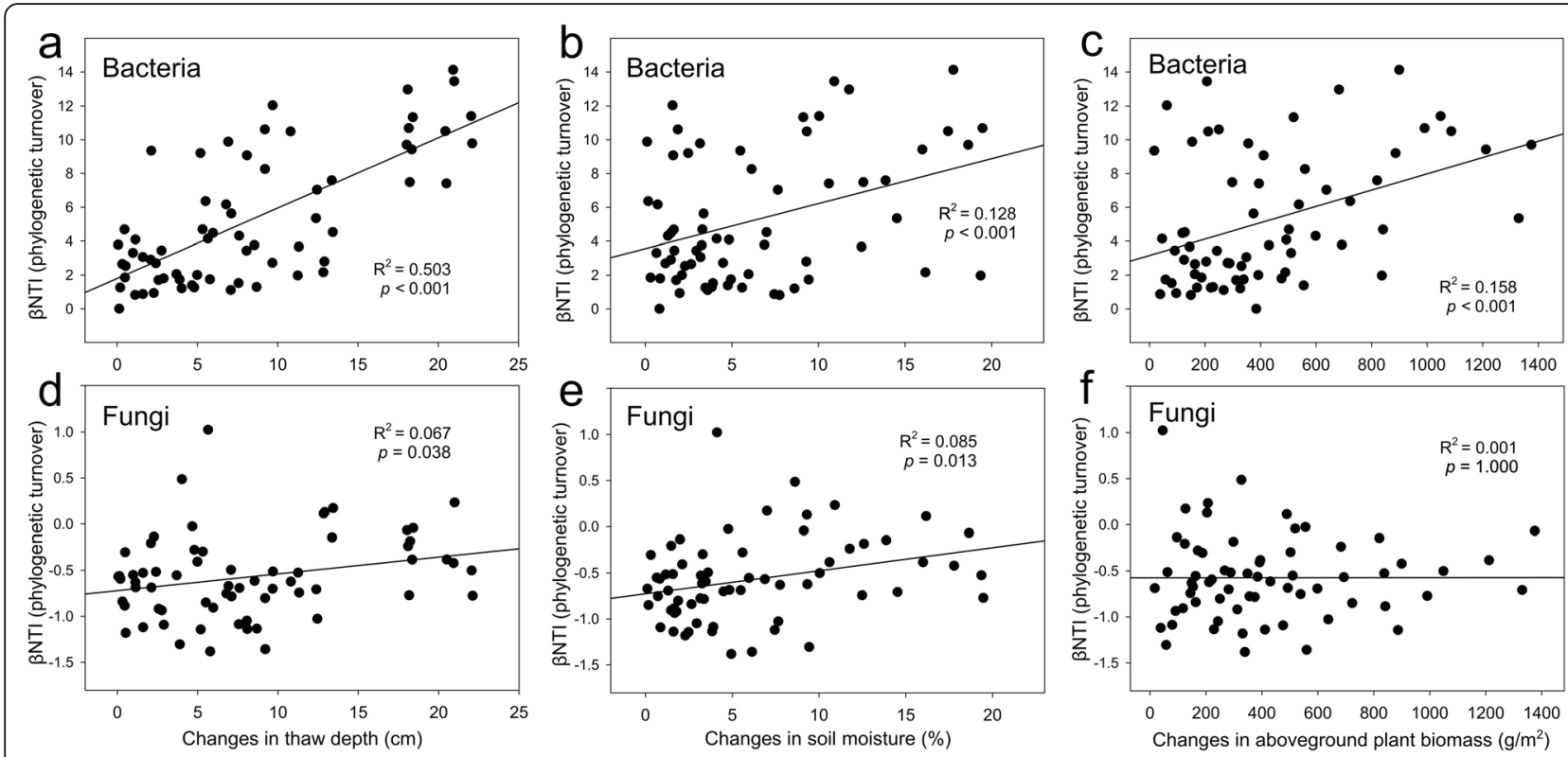

Fig. 4 Linear regressions between pairwise microbial community phylogenetic turnovers (Beta Nearest Taxon Index, $\beta N T I$ ) and pairwise differences of plant and soil factors. Phylogenetic turnover metrics are related to changes in $\mathbf{a}$ soil thaw depth, $\mathbf{b}$ soil moisture and $\mathbf{c}$ aboveground plant biomass for bacterial communities, and changes in $\mathbf{d}$ soil thaw depth, e soil moisture and $\mathbf{f}$ aboveground plant biomass for fungal communities. The 66 points in each sub-figure represent the 66 pairwise differences generated from the 6 warmed samples and 6 control samples

by the winter warming treatment because soil temperature in the growing season remained unchanged (Additional file 1: Table S1).

Thaw of permafrost regions has long been considered to have profound effects on local hydrological, thermal, and $\mathrm{C}$ dynamics [3, 18, 22, 23]. We found that warming increased the thaw depth [24], which was the strongest factor linking to bacterial phylogenetic assembly (Fig. 4a), community composition (Additional file 1: Figure S6a), and network topology (Additional file 1: Figure S2). Consistently, deterministic processes (e.g., selection) played a more crucial role in shaping bacterial communities under warming (Additional file 1: Figure S5a). These results are consistent with a recent study of permafrost regions showing that changes in thaw depth induced changes in soil diazotrophic communities [25]. Moreover, the divergence of bacterial communities observed in this study under experimental warming manifested as increases of withingroup $\beta$-diversity (Fig. 1c), might be a phenomenon generalizable to other ecosystems, since bacterial communities in a tallgrass prairie site were also divergent within warming replicates [26]. In sharp contrast, fungal communities remained unaltered by warming (Table 1). This could arise from the large variability of fungal communities as shown by the larger standard error of Faith's $P D$ for the fungi than for the bacteria (Fig. 1a, b).

The bacterial network of warmed samples exhibited higher average connectivity and shorter average geodesic distance than that of control samples (Additional file 1:
Table S2), suggestive of a more complex network and denser interactions. The dense network is likely associated with deterministic processes (e.g., environmental filtering) [27]. Accordingly, we detected a higher contribution of deterministic processes under warming conditions (Additional file 1: Figure S5a).

Similar to the results of the 1.5-year warming at our study site [4], the relative abundance of functional genes associated with both aerobic and anaerobic $\mathrm{C}$ decomposition was increased by 5 -year warming. These results could be crucial in assessing $C$ dynamics in permafrost regions since the warming-induced thaw of permafrost regions exposes previously protected $\mathrm{C}$ stock to microbial activity. These findings also provide a mechanistic explanation for the recent observation that warming at our study site increased the annual cellulose decomposition rate at a soil depth of $0-10 \mathrm{~cm}$ by a factor of two [24]. In addition, the relative abundance of functional genes associated with recalcitrant $\mathrm{C}$ decomposition (e.g., aromatics and lignin, Fig. 2a) was increased by warming, which is in accordance with our finding that the relative abundance of the genus Chitinophaga, a strong chitinolytic taxa [28], was also increased by warming. Therefore, a potential increase in the decomposition of recalcitrant $\mathrm{C}$ is expected.

Field warming experiments have demonstrated that an initial increase of $\mathrm{CO}_{2}$ flux gradually subsides over time, returning to pre-warming values [29-34]. However, we observed persistent, enhanced ecosystem respiration 
after 5-year warming, which could result from a stimulated microbial decomposition of soil organic C (Additional file 1: Table S1). This phenomenon may arise from three mechanisms: (1) continuous warming increases the thaw depth, creating a crucial difference in the soil environment between warming and control plots, so acclimatization of microbial communities to warming is unlikely to occur; (2) since the temperature sensitivity of recalcitrant SOC is higher than labile SOC $[16,30]$, a higher microbial functional capacity of recalcitrant $\mathrm{C}$ decomposition under warming can aggravate soil $C$ instability related to ecosystem respiration; and (3) the warming effect in permafrost regions is often more substantial for deeper soils [25], which contributes to ecosystem respiration. Therefore, we project that the soil microbial community would continue to provide positive feedback to climate warming.

All $\mathrm{N}$ cycling-associated genes exhibited higher relative abundance in warmed samples (Additional file 1: Figure S4a), which was consistent with the observations that both inorganic $\mathrm{N}$ availability and foliar $\mathrm{N}$ pools were increased by warming at our study site [12], and that soil nutrient contents were generally stimulated by warming in the tundra ecosystem [12, 13]. The larger nutrient pool available to plants could increase aboveground plant biomass (Additional file 1: Table S1). However, this higher plant productivity may only partially offset $C$ loss, as a previous study of the Alaskan tundra observed a negative net ecosystem exchange due to a larger loss of $C$ in deep soils than was increased by plant production [35]. Similarly, adding organic $\mathrm{N}$ to the active layer above the permafrost soils increased SOM decomposition by $2-3$-fold [36]. Therefore, an increased soil nutrient availability associated with warming may further amplify $\mathrm{C}$ loss and consequently impose positive feedback to climate warming.

Collectively, our results show that 5-year warming significantly altered the bacterial composition and functional structure of microbial communities in permafrost regions, revealing an evolving sensitivity to warming. Soil thaw depth was the strongest factor shaping bacterial taxonomic composition, $\mathrm{C}$ decomposition potential, and network topological properties, demonstrating that warming-induced thaw of permafrost regions fundamentally restructures the associated bacterial communities. Therefore, we project that microbial responses to longterm warming will lead to positive feedback enhancing $\mathrm{C}$ decomposition in tundra regions.

\section{Methods}

\section{Field site description and soil sampling}

Established in 2008, the CiPEHR project is located within a discontinuous permafrost region in the northern foothills of the Alaska Range ( 670 m elevation) at the Eight Mile study site, AK, USA (63⒌ $52^{\prime} 59^{\prime \prime}$ N, $149^{\circ} 13^{\prime}$ 32 " W) [11, 37]. Soils in the experimental site are gelisols and comprise a 45-65-cm-thick organic horizon above a cryoturbated mineral mixture of glacial till and loess. The active layer, which thaws annually, is $50-60 \mathrm{~cm}$ thick. The site had a mean annual air temperature of $-1.45 \pm 0.25^{\circ} \mathrm{C}$ from 1977 to 2013 and a mean growing season precipitation of $216 \pm 24 \mathrm{~mm}$ from 2004 to 2013 . The dominant vegetation is a tussock-forming sedge, Eriophorum vaginatum. More detailed information on this site is available elsewhere [37].

Soils have been warmed since 2008 via snow fences (1.5 $\mathrm{m}$ tall, $8 \mathrm{~m}$ long), which act as insulators to increase the depth of the snow layer. Six snow fences are arranged in three blocks of two each, with each fence representing a warming-control plot pair. Each block is approximately $100 \mathrm{~m}$ apart and fences within a block are $5 \mathrm{~m}$ apart. Snow removal is conducted in the early spring (March 8-15) to avoid moisture and meltdown effects of the additional snow. In May 2013, surface soil samples at a depth of $0-15 \mathrm{~cm}$ were collected from both warming and control plots ( 6 replicates each), and then used for microbial community and environmental factor analyses.

\section{Measurement of environmental factors}

Soil temperature at the depths of 5 and $10 \mathrm{~cm}$ was measured every half an hour in each plot using constantancopper thermocouples and recorded using CR1000 data loggers (Campbell Scientific, Logan, UT, USA). Sitecalibrated CS616 water content reflectometer probes (Campbell Scientific, Logan, UT, USA) were used to measure volumetric water content (moisture) at a depth of 0-15 cm. CS450 pressure transducers (Campbell Scientific, Logan, UT, USA) were used to continuously measure water table depth. The thaw depth was measured weekly during the growing season using a metal probe. Aboveground biomass was determined by a nondestructive point-frame method using a $60 \times 60 \mathrm{~cm}$ frame with $8 \times 8 \mathrm{~cm}$ grids, and species identity and tissue type (leaf, stem or fruit) for plants touching the rod ("hits") were recorded as previously described [11]. Soil $\mathrm{C}$ and N contents were measured using an ECS 4010 Elemental Analyzer (Costech Analytical Technologies, Valencia, CA, USA). $\mathrm{CH}_{4}$ fluxes from each plot were measured as previously described [24], using a HP 5890 gas chromatograph (Hewlett-Packard, Palo Alto, CA, USA) equipped with a flame ionization detector and a molecular sieve 13X packed column. Ecosystem respiration was measured using an LI-820 infrared gas analyzer (LI-COR Biosciences, Lincoln, NE, USA) connected to a chamber placed on the plot base and covered by a dark tarp to exclude photosynthesis. The mean values of growing season soil temperature, soil moisture, 
water table depth, thaw depth, ecosystem respiration, and $\mathrm{CH}_{4}$ flux data from the 2012 growing season and winter soil temperature during the winter of late 2012early 2013 were calculated.

\section{Soil DNA extraction}

Soil DNA was extracted from $3 \mathrm{~g}$ of each soil sample by freeze-grinding mechanical cell lysis as described previously [38] and then purified with a PowerMax Soil DNA Isolation Kit (MO BIO, San Francisco, CA, USA). A NanoDrop ND-1000 spectrophotometer (NanoDrop Technologies Inc., Wilmington, DE, USA) was used to assess DNA quality using absorbance ratios of 260:280 and 260:230 nm. Final DNA concentrations were quantified using a Quant-iT PicoGreen dsDNA Assay kit (Invitrogen, Carlsbad, CA) with a FLUOstar OPTIMA fluorescence plate reader (BMG LabTech, Jena, Germany).

\section{High-throughput amplicon sequencing and raw data processing}

The V4 hypervariable region of $16 \mathrm{~S}$ rRNA gene was amplified with the primer pair 515F (5'-GTGCCAGC MGCCGCGGTAA-3') and 806R (5'-GGACTACH VGGGTWTCTAAT-3'). The fungal internal transcribed spacer (ITS) was amplified with the primer pair ITS7F (5'-GTGARTCATCGARTCTTTG-3') and ITS4R (5'TCCTCCGCTTATTGATATGC-3'). A two-step PCR protocol was used to avoid bias introduced by long sequencing primers [39], which was an initial denaturation at $94{ }^{\circ} \mathrm{C}$ for $1 \mathrm{~min}$, then 10 cycles (first step) or 20 cycles (second step) of $94{ }^{\circ} \mathrm{C}$ for $20 \mathrm{~s}, 53{ }^{\circ} \mathrm{C}$ (16S rRNA gene) or $52{ }^{\circ} \mathrm{C}$ (ITS) for $25 \mathrm{~s}, 68^{\circ} \mathrm{C}$ for $45 \mathrm{~s}$, followed by a final 10 -min extension at $68{ }^{\circ} \mathrm{C}$. The amplicons were pairedend sequenced $(2 \times 150)$ on a MiSeq sequencer (Illumina, San Diego, CA, USA). Sequences were denoised and processed on an online pipeline (www.ou.edu/ieg/ tools/data-analysis-pipeline). Specifically, sequences were trimmed using BTRIM with a threshold quality score greater than 20 within a 5 bp window size and a minimum length of $100 \mathrm{bp}$. Forward and reverse reads with at least a 50 bp overlap and no more than $5 \%$ mismatches were joined using FLASH [40]. After removing sequences with ambiguous $\mathrm{N}$ bases, joined sequences with lengths between 245 and 260 bp for 16S rRNA, and between 100 and $450 \mathrm{bp}$ for ITS were subjected to chimera removal by U-Chime as previously described $[41,42]$. OTUs were clustered through Uclust at a $97 \%$ similarity level [41]. Taxonomic assignment was conducted through the RDP classifier [43] with a confidence cutoff of 0.5 , and singletons were removed. The remaining sequences were randomly resampled to a depth of 34673 reads per sample for $16 \mathrm{~S}$ rRNA gene sequences, and 19242 reads per sample for fungal ITS.

\section{GeoChip 5.0 analyses and raw data processing}

Microbial functional genes were analyzed using the 180 $\mathrm{K}$ version of GeoChip 5.0M (Agilent Technologies Inc., Santa Clara, CA, USA), which contains 161961 probes targeting 1447 gene families involved in 12 major functional categories, such as C, N, P, and S cycling [19]. For each sample, $1 \mu \mathrm{g}$ of soil DNA was labeled with $\mathrm{Cy} 3$ using random primers, dNTP solution and Klenow, purified with the Qiagen QIAquick Kit (Qiagen, Germantown, MD, USA) and dried using a SpeedVac (Thermo Fisher Scientific Inc., Waltham, MA, USA). Labeled samples were hybridized onto GeoChip at $67^{\circ} \mathrm{C}$ in the presence of $10 \%$ formamide for $24 \mathrm{~h}$. After hybridization, the arrays were washed, dried, and scanned at $100 \%$ laser power and photomultiplier tube on an MS200 Nimblegen microarray scanner (Roche Nimblegen, Madison, WI, USA). Scanned images were processed and transformed into signal intensities with Agilent's Data Extraction software. Raw signal intensity files were uploaded onto an online pipeline (www.ou.edu/ieg/tools/data-anal ysis-pipeline) for further data quality filtering, normalization and data analyses. We normalized the signal intensity of each spot by relative abundance among all samples, removed spots with a signal-to-noise ratio $(\mathrm{SNR})<2$, a signal intensity $<1.3$ of background, or outliers based on judgements of 2 standard deviations.

\section{Molecular ecological network analysis}

Phylogenetic molecular ecological networks (pMENs) were constructed from both the 16S rRNA gene and ITS sequences, using a random matrix theory (RMT)-based network pipeline (http://ieg4.rccc.ou.edu/MENA/) [44]. To ensure reliability, only OTUs detected in all six replicates were used for network construction. In brief, a matrix containing Spearman's rho correlation between any pair of OTUs was generated. The threshold of similarity coefficients ( $r$ values of the Spearman's rho correlation) for network construction was automatically determined when the nearest-neighbor spacing distribution of eigenvalues transitioned from Gaussian orthogonal ensemble to Poisson distributions [45]. Consequently, a threshold of 0.980 was used for bacterial networks of warming and control samples, 0.915 was used for the fungal network of control samples, and 0.920 was used for the fungal network of warming samples. To identify environmental factors important for network topology, environmental factors were also incorporated into networks, as RMTbased networks were designed to allow the use of multiple data types [45]. Random networks corresponding to all pMENs were constructed using the Maslov-Sneppen procedure with the same network size and average number of links to verify the system-specificity, sensitivity, and robustness of the empirical networks [46]. Network graphs were visualized with Cytoscape 3.5.1 software. 


\section{Statistical analyses}

Various statistical analyses were conducted with the package vegan (v2.3-2) [47] in $\mathrm{R}$ software version 3.2.2 [48]. Two-tailed Monte-Carlo permutation $t$ tests and permutation analysis of variance (PERMANOVA) were used to examine the statistical significance of differences between microbial taxa, functional gene abundance or environmental factors (10000 permutations were generated for each test). Three complementary dissimilarity tests (multi-response permutation procedure [49], analysis of similarity [50], and non-parametric multivariate analysis of variance [51]) and detrended correspondence analysis [52] (DCA) were used to examine community differences. Canonical correspondence analysis (CCA) was used to detect linkages between microbial communities and environmental factors, with a threshold variance inflation factor of less than 20 to select independent environmental factors. To evaluate community assembly mechanisms, stochastic ratios were calculated with a modified stochastic ratio method [53] on the IEG Statistical Analysis Pipeline (www.ou.edu/ieg/ tools/data-analysis-pipeline) based on phylogenetic (Beta-Mean Nearest Taxon Distance, $\beta M N T D)$ metrics. Linear models were constructed to detect correlations among microbial communities and $\mathrm{C}$ fluxes with the package stats (v3.5.2) in $\mathrm{R}$ [48], and tested for significance by permutation tests with the package lmPerm (v2.1.0) [54].

\section{Supplementary information}

Supplementary information accompanies this paper at https://doi.org/10. 1186/s40168-019-0778-3.

Additional file 1: Table S1. Summary of environmental factors. Table S2. Major topological properties of the empirical pMENs of bacterial and fungal communities in the control and warming sites and the associated random networks. Figure S1. Microbial taxonomic composition of (a) bacterial communities and (b) fungal communities at the phylum level (for bacterial communities, Proteobacterial Classes are juxtaposed with other Phyla). Phyla with abundance less than $1 \%$ were combined to Others. Figure S2. Networks among environmental factors and microbial communities. (a) Bacterial communities from warming plots; (b) Bacterial communities from control plots; (c) fungal communities from warming plots, and (d) fungal communities from control plots. Red nodes represent environmental factors, blue nodes represent OTUs directly connected to environmental factors, grey nodes represent OTUs indirectly connected to environmental factors. Grey edges represent positive correlations, and red edges represent negative correlations. Abbreviations: Plant, aboveground plant biomass; Moisture, soil moisture; Bulk density, bulk soil density; C, soil total carbon; N, soil total nitrogen, and C/N, soil carbon/nitrogen ratio. Figure S3. The linear regressions between pairwise similarities of (a) bacterial community composition and functional structure (GeoChip data), and (b) fungal community composition and functional structure. Bray-Curtis distance was used for the similarity calculations. Figure S4. Differences of average normalized signal intensities of representative genes involved in (a) nitrogen cycling, (b) phosphorus cycling, and (c) sulfur cycling. (a) Red gene names represent genes with a higher average normalized signal intensity in warming samples, whose percentages of changes are indicated in parentheses. (b \& c) Blue bars represent the average normalized signal intensity of gene probes in control samples, and red bars represent the average normalized signal intensity of gene probes in warming samples. Error bars represent standard errors. The differences between warming and control samples were tested using ANOVA, with * indicating $p<0.050$. Figure S5. Overall community stochasticity on the basis of phylogenetic metric of (a) bacterial communities and (b) fungal communities. The data for each bar contains $n$ $=15$ within-group pairwise comparisons calculated from 6 biological replicates. Figure $\mathbf{S 6}$. Relationship between microbial community composition or functional structure and environmental factors revealed by canonical correspondence analysis (CCA) of (a) bacterial communities (red dots represent warming samples, and blue dots represent control samples) and environmental variables (arrows), (b) fungal communities and environmental variables; and (c) microbial functional structure and environmental variables. All CCA models are significant $(p<0.050)$.

\section{Authors' contributions}

JZ, EAGS, YL, JMT, JRC, YY, CRP, and KTK developed the original concepts. RGB and KTK collected soil samples. XT, CW and JF extracted DNA. CW carried out 165 rRNA gene and ITS amplicon sequencing experiments. JF, $C W, Y Q$, and ZJS processed the data of amplicon sequences. QY and XZ performed GeoChip microarray experiments. JF, CW, and DN performed molecular ecological network analysis and statistical analyses. JF, CW, YY, and JZ wrote the paper. JL, MMY, XG, DN, ZH, JDVN, LW, and CRP edited the manuscript. All authors were given the opportunity to review the results and comment the manuscript. All authors read and approved the final manuscript.

\section{Funding}

This work was supported by the US Department of Energy, Office of Science, Genomic Science Program under Award Numbers DE-SC0004601 and DESC0010715, the NSF LTER program, National Science Foundation of China (41430856, 41877048, and 41825016), and the Office of the Vice President for Research at the University of Oklahoma.

\section{Availability of data and materials}

Raw sequences of 165 rRNA and ITS amplicon genes are available in NCBI SRA database (www.ncbi.nlm.nih.gov/sra) under accession number PRJNA506455. Raw data of GeoChip experiments can be accessed through the URL (129.15.40.254/NewIEGWebsiteFiles/publications/SupplData/CiPEHR JiajieFENG_Raw_GeoChip_Data.txt) and (129.15.40.254/NewIEGWebsiteFiles/ publications/SupplData/CiPEHR_JiajieFENG_Normalized_GeoChip_Data.txt).

Ethics approval and consent to participate

Not applicable.

\section{Consent for publication}

Not applicable.

\section{Competing interests}

The authors declare that they have no competing interests.

\section{Author details}

${ }^{1}$ Institute for Environmental Genomics, Department of Microbiology and Plant Biology, University of Oklahoma, Norman, OK 73019, USA. ${ }^{2}$ State Key Joint Laboratory of Environment Simulation and Pollution Control, School of Environment, Tsinghua University, Beijing 100084, China. ${ }^{3}$ Environmental Microbiomics Research Center, School of Environmental Science and Engineering, Sun Yat-Sen University, Guangzhou 510006, China. ${ }^{4}$ Guangdong Provincial Key Laboratory of Environmental Pollution Control and Remediation Technology, School of Environmental Science and Engineering, Sun Yat-Sen University, Guangzhou 510006, China. ${ }^{5}$ School of Minerals Processing and Bioengineering, Central South University, Changsha 410083, China. ${ }^{6}$ School of Forest Resources and Conservation, University of Florida, Gainesville, FL 32611, USA. ${ }^{7}$ Center for Fundamental and Applied Microbiomics, Arizona State University, Mesa, AZ 85212, USA. ${ }^{8}$ College of Integrative Sciences and Arts, Faculty of Science and Mathematics, Arizona State University, Mesa, Arizona 85212, USA. ${ }^{9}$ Center for Microbial Ecology, Michigan State University, East Lansing, MI 48824, USA. ${ }^{10}$ School of Civil and Environmental Engineering, School of Biology, and Center for Bioinformatics and Computational Genomics, Georgia Institute of Technology, Atlanta, GA 30332, USA. ${ }^{11}$ Center for Ecosystem Science and Society, Northern Arizona University, Flagstaff, AZ 86011, USA. ${ }^{12}$ DOE Great Lakes Bioenergy Research 
Center, Michigan State University, East Lansing, Ml 48824, USA. ${ }^{13}$ Earth and Environmental Sciences, Lawrence Berkeley National Laboratory, Berkeley, CA 94720, USA.

Received: 23 September 2019 Accepted: 23 December 2019

Published online: 17 January 2020

\section{References}

1. Schuur EAG, Vogel JG, Crummer KG, Lee H, Sickman JO, Osterkamp TE. The effect of permafrost thaw on old carbon release and net carbon exchange from tundra. Nature. 2009:459(7246):556-9.

2. Schuur EAG, Bockheim J, Canadell JG, Euskirchen E, Field CB, Goryachkin SV, et al. Vulnerability of permafrost carbon to climate change: Implications for the global carbon cycle. Bioscience. 2008:58(8):701-14.

3. Schuur EAG, Abbott B, Network PC. High risk of permafrost thaw. Nature. 2011:480(7375):32-3.

4. Xue K, Yuan MM, Shi ZJ, Qin Y, Deng Y, Cheng L, et al. Tundra soil carbon is vulnerable to rapid microbial decomposition under climate warming. Nature Climate Change. 2016;6(6):595

5. Pries $\mathrm{CEH}$, Schuur EA, Crummer KG. Holocene carbon stocks and carbon accumulation rates altered in soils undergoing permafrost thaw. Ecosystems. 2012;15(1):162-73.

6. Tarnocai C, Canadell J, Schuur E, Kuhry P, Mazhitova G, Zimov S. Soil organic carbon pools in the northern circumpolar permafrost region. Global biogeochemical cycles. 2009;23(2).

7. Schuur EAG, McGuire AD, Schadel C, Grosse G, Harden JW, Hayes DJ, et al. Climate change and the permafrost carbon feedback. Nature. 2015; 520(7546):171-9.

8. Stocker TF, Qin D, Plattner G-K, Tignor MM, Allen SK, Boschung J, et al. Climate Change 2013: The physical science basis. contribution of working group I to the fifth assessment report of IPCC the intergovernmental pane on climate change. Cambridge University Press; 2014.

9. Lawrence DM, Slater AG, Swenson SC. Simulation of present-day and future permafrost and seasonally frozen ground conditions in CCSM4. Journal of Climate. 2012;25(7):2207-25.

10. Grosse G, Harden J, Turetsky M, AD MG, Camill P, Tarnocai C, et al. Vulnerability of high-latitude soil organic carbon in North America to disturbance. Journal of Geophysical Research: Biogeosciences. 2011; 116(G4).

11. Natali SM, Schuur EAG, Rubin RL. Increased plant productivity in Alaskan tundra as a result of experimental warming of soil and permafrost. Journal of Ecology. 2012;100(2):488-98.

12. Salmon VG, Soucy P, Mauritz M, Celis G, Natali SM, Mack MC, et al. Nitrogen availability increases in a tundra ecosystem during five years of experimental permafrost thaw. Global Change Biology. 2016;22(5):1927-41

13. Deane-Coe KK, Mauritz M, Celis G, Salmon V, Crummer KG, Natali SM, et al. Experimental Warming Alters Productivity and Isotopic Signatures of Tundra Mosses. Ecosystems. 2015;18(6):1070-82.

14. Deng J, Gu Y, Zhang J, Xue K, Qin Y, Yuan M, et al. Shifts of tundra bacterial and archaeal communities along a permafrost thaw gradient in A laska. Molecular ecology. 2015;24(1):222-34

15. Elberling B, Michelsen A, Schädel C, Schuur EA, Christiansen HH, Berg L, et al. Long-term CO 2 production following permafrost thaw. Nature Climate Change. 2013:3(10):890.

16. Bracho R, Natali S, Pegoraro E, Crummer KG, Schädel C, Celis G, et al. Temperature sensitivity of organic matter decomposition of permafrostregion soils during laboratory incubations. Soil Biology and Biochemistry. 2016;97:1-14.

17. Webb EE, Schuur EAG, Natali SM, Oken KL, Bracho R, Krapek JP, et al. Increased wintertime $\mathrm{CO} 2$ loss as a result of sustained tundra warming. Journal of Geophysical Research: Biogeosciences. 2016;121(2):249-65.

18. Pries $C E H$, Schuur EA, Natali SM, Crummer KG. Old soil carbon losses increase with ecosystem respiration in experimentally thawed tundra. Nature Climate Change. 2016;6(2):214

19. Zhang Y, Ling J, Yang Q, Wen C, Yan Q, Sun $H$, et al. The functional gene composition and metabolic potential of coral-associated microbial communities. Scientific reports. 2015:5:16191

20. Webb CO, Ackerly DD, McPeek MA, Donoghue MJ. Phylogenies and community ecology. Annual review of ecology and systematics. 2002;33(1): 475-505.
21. Graham DE, Wallenstein MD, Vishnivetskaya TA, Waldrop MP, Phelps TJ, Pfiffner SM, et al. Microbes in thawing permafrost: the unknown variable in the climate change equation. The ISME journal. 2012;6(4):709.

22. O'Donnell JA, Jorgenson MT, Harden JW, McGuire AD, Kanevskiy MZ, Wickland KP. The Effects of Permafrost Thaw on Soil Hydrologic, Thermal, and Carbon Dynamics in an Alaskan Peatland. Ecosystems. 2012;15(2):213-29.

23. Pries $\mathrm{CEH}$, Schuur EA, Crummer KG. Thawing permafrost increases old soil and autotrophic respiration in tundra: Partitioning ecosystem respiration using $813 C$ and $\triangle 14 C$. Global Change Biology. 2013;19(2):649-61.

24. Natali SM, Schuur EAG, Mauritz M, Schade JD, Celis G, Crummer KG, et al. Permafrost thaw and soil moisture driving $\mathrm{CO} 2$ and $\mathrm{CH} 4$ release from upland tundra. Journal of Geophysical Research-Biogeosciences. 2015;120(3): 525-37.

25. Feng J, Penton CR, He Z, Van Nostrand JD, Yuan MM, Wu L, et al. LongTerm Warming in Alaska Enlarges the Diazotrophic Community in Deep Soils. mBio. 2019;10(1):e02521-18.

26. Guo X, Feng J, Shi Z, Zhou X, Yuan M, Tao X, et al. Climate warming leads to divergent succession of grassland microbial communities. Nature Climate Change. 2018;8(9):813-8.

27. Cornwell WK, Schwilk DW, Ackerly DD. A trait-based test for habitat filtering: convex hull volume. Ecology. 2006;87(6):1465-71.

28. Sangkhobol V, Skerman V. Chitinophaga, a new genus of chitinolytic myxobacteria. International Journal of Systematic and Evolutionary Microbiology. 1981;31(3):285-93.

29. Luo Y, Wan S, Hui D, Wallace LL. Acclimatization of soil respiration to warming in a tall grass prairie. Nature. 2001;413(6856):622-5.

30. Knorr W, Prentice IC, House Jl, Holland EA. Long-term sensitivity of soil carbon turnover to warming. Nature. 2005;433(7023):298-301.

31. Oechel WC, Vourlitis GL, Hastings SJ, Zulueta RC, Hinzman L, Kane D. Acclimation of ecosystem $\mathrm{CO} 2$ exchange in the Alaskan Arctic in response to decadal climate warming. Nature. 2000;406(6799):978-81.

32. Melillo J, Steudler P, Aber J, Newkirk K, Lux H, Bowles F, et al. Soil warming and carbon-cycle feedbacks to the climate system. Science. 2002;298(5601): 2173-6.

33. Eliasson PE, McMurtrie RE, Pepper DA, Strömgren M, Linder S, Ågren Gl. The response of heterotrophic CO2 flux to soil warming. Global Change Biology. 2005;11(1):167-81.

34. Rustad L, Campbell J, Marion G, Norby R, Mitchell M, Hartley A, et al. A meta-analysis of the response of soil respiration, net nitrogen mineralization, and aboveground plant growth to experimental ecosystem warming. Oecologia. 2001;126(4):543-62.

35. Mack MC, Schuur EAG, Bret-Harte MS, Shaver GR, Chapin FS. Ecosystem carbon storage in arctic tundra reduced by long-term nutrient fertilization Nature. 2004;431(7007):440-3.

36. Wild B, Schnecker J, Alves RJE, Barsukov P, Bárta J, Čapek P, et al. Input of easily available organic $C$ and $N$ stimulates microbial decomposition of soil organic matter in arctic permafrost soil. Soil Biology and Biochemistry. 2014; 75:143-51.

37. Natali SM, Schuur EAG, Trucco C, Pries CEH, Crummer KG, Lopez AFB. Effects of experimental warming of air, soil and permafrost on carbon balance in Alaskan tundra. Global Change Biology. 2011:17(3):1394-407.

38. Zhou J, Bruns MA, Tiedje JM. DNA recovery from soils of diverse composition. Applied and environmental microbiology. 1996:62(2):316-22.

39. Wu L, Wen C, Qin Y, Yin H, Tu Q, Van Nostrand JD, et al. Phasing amplicon sequencing on Illumina Miseq for robust environmental microbial community analysis. BMC microbiology. 2015;15(1):125.

40. Magoč T, Salzberg SL. FLASH: fast length adjustment of short reads to improve genome assemblies. Bioinformatics. 2011;27(21):2957-63.

41. Edgar RC, Haas BJ, Clemente JC, Quince C, Knight R. UCHIME improves sensitivity and speed of chimera detection. Bioinformatics. 2011;27(16): 2194-200.

42. Hao Z, Li L, Fu Y, Liu H. The influence of bioregenerative life-support system dietary structure and lifestyle on the gut microbiota: a 105-day groundbased space simulation in Lunar Palace 1. Environmental microbiology. 2018;20(10):3643-56

43. Wang Q, Garrity GM, Tiedje JM, Cole JR. Naive Bayesian classifier for rapid assignment of rRNA sequences into the new bacterial taxonomy. Appl Environ Microb. 2007:73(16):5261-7.

44. Yang Y, Harris DP, Luo F, Xiong W, Joachimiak M, Wu L, et al. Snapshot of iron response in Shewanella oneidensis by gene network reconstruction. BMC Genomics. 2009;10:131. 
45. Deng Y, Jiang Y-H, Yang Y, He Z, Luo F, Zhou J. Molecular ecological network analyses. BMC bioinformatics. 2012;13(1):113.

46. Maslov S, Sneppen K. Specificity and stability in topology of protein networks. Science. 2002:296(5569):910-3.

47. Oksanen J, Blanchet FG, Kindt R, Legendre P, O'hara R, Simpson GL et al. Vegan: community ecology package. R package version 1.17-4. http://cran rproject org> Acesso em. 2010;23:2010.

48. R Core Team. R: A language and environment for statistical computing; 2013.

49. Sickle JV. Using mean similarity dendrograms to evaluate classifications. Journal of Agricultural, Biological, and Environmental Statistics. 1997. p. 370-88,

50. Clarke KR. Non-parametric multivariate analyses of changes in community structure. Australian journal of ecology. 1993;18(1):117-43.

51. Zapala MA, Schork NJ. Multivariate regression analysis of distance matrices for testing associations between gene expression patterns and related variables. Proceedings of the national academy of sciences. 2006;103(51): 19430-5.

52. Oksanen J, Minchin PR. Instability of ordination results under changes in input data order: explanations and remedies. Journal of Vegetation Science. 1997;8(3):447-54.

53. Zhou J, Deng Y, Zhang P, Xue K, Liang Y, Van Nostrand JD, et al. Stochasticity, succession, and environmental perturbations in a fluidic ecosystem. Proceedings of the National Academy of Sciences. 2014;111(9): E836-45.

54. Wheeler B, Torchiano M. ImPerm: Permutation tests for linear models. R package version 1.1-2. 2010. Available at: http://cran.r-project.org/web/ packages/lmPerm/.

\section{Publisher's Note}

Springer Nature remains neutral with regard to jurisdictional claims in published maps and institutional affiliations.

Ready to submit your research? Choose BMC and benefit from:

- fast, convenient online submission

- thorough peer review by experienced researchers in your field

- rapid publication on acceptance

- support for research data, including large and complex data types

- gold Open Access which fosters wider collaboration and increased citations

- maximum visibility for your research: over $100 \mathrm{M}$ website views per year

At $\mathrm{BMC}$, research is always in progress.

Learn more biomedcentral.com/submissions 